Fourth International Conference on Sustainable Construction Materials and Technologies http://www.claisse.info/Proceedings.htm

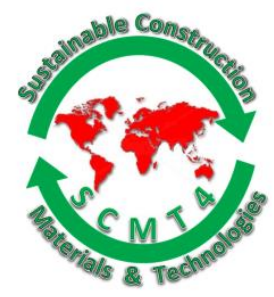

SCMT4

Las Vegas, USA, August 7-11, 2016

\title{
Structural Concrete Made with Recycled Aggregates for Sustainable Concrete Design
}

\author{
Giacomo Moriconi ${ }^{1}$, and Tarun R. Naik ${ }^{2}$ \\ ${ }^{1}$ Department of Science and Engineering of Matter, Environment and Urban Planning, Università \\ Politecnica delle Marche, Italy. Email: 〈g.moriconi@univpm.it> \\ ${ }^{2}$ Emeritus Professor, Formerly Research Professor and Academic Program Director, UWM Center for \\ By-Products Utilization, University of Wisconsin-Milwaukee, Milwaukee, Wisconsin, USA. Email: \\ <tarun@uwm.edu>
}

\begin{abstract}
The sustainability concept, although intuitive, represents a complex set of criterion, involving conflicting environmental, social, and economical issues. For instance, a basic requirement determining the sustainability concerns structural safety, which must be guaranteed throughout its entire service life, by taking precautionary measures even against unpredictable actions. This issue, even if consistent with environmental sustainability, may prove conflicting with economical sustainability. Therefore, the sustainability evaluation of a structural design choice may represent an important support as a decisionmaking tool, suggesting the most sustainable and generally more innovative choice, since the intersection between the three sustainability issues marks the area for innovation. Within this framework, the use of recycled aggregates from construction and demolition (C\&D) waste is analyzed for the production of structural concrete, supported by state-of-the-current knowledge and relevant ongoing current research carried out in the concrete technology field in Italy and elsewhere.
\end{abstract}

\section{INTRODUCTION}

History teaches that the construction technology evolution since its dawn has been characterized by more or less innovative and successful activity of recovering and recycling materials. Historic examples are the utilization of finely ground earthenware as "pozzolanic" addition to the binders used by the Phoenicians since X century B.C., or, even more, the use of amphorae scraps, likely from the manufacturing of wine containers, as lightweight aggregates for the concrete utilized by the Romans in the III century B.C. to build the piers of the Port of Cosa, the ancient Roman colony known for fishery.

In the last few decades, growing awareness towards more sustainable design has motivated many researchers (some of which are reported in the section on references at the end of this paper). These references demonstrate the extent of the time span, geographical areas and the interest for this subject matter, to re-investigate recycling procedures in the area of materials and construction technologies [Malhotra 1978; RILEM 1992; Mehta 1997, 1999, 2009; Tittarelli and Moriconi 2002; Moriconi 2005; Corinaldesi and Moriconi 2003; Naik and Moriconi 2005; Bassan et al. 2006; Malešev et al. 2010; Ho et al. 2013]. These studies, together with many numerous others reported in the literature, have already proven the viability of producing concrete for structural use by using recycled aggregates from the demolition of buildings and other infastuctures at the end of their service life. 
On the basis of the reported results, a comparison can be made between the performance of an ordinary concrete and the concrete of the same strength class prepared with recycled aggregates. In particular, at an equivalent compressive strength, the recycled aggregate concrete shows [Corinaldesi and Moriconi 2010]:

- a lower tensile strength (about 10\%);

- a lower elastic modulus (about 20\%);

- the same bond strength with the steel reinforcement;

- the same vulnerability to shrinkage cracking;

- durability characteristics at least equivalent in terms of resistance to freeze-thawing, sulfate attack, penetration of aggressive agents; and,

- no problems of leaching of potentially hazardous substances to the environment [Sani et al. 2005].

Moreover, based on such results, the technical regulations could not ignore transnational guidelines (such as, $2000 \mathrm{EU}$ directive) with the following recommendations:

- limitation to landfill disposal;

- incentives for waste selection at source and waste recycling;

- specific conditions to develop recycled materials;

- inclusion of waste management as an integral part of building permit and demolition permit; and,

- incentives for the use of recycled materials in public works.

Following the enactment of Standard EN 12620 "Aggregates for concrete", stating the properties of aggregates and fillers obtained from processing of natural, artificial, or recycled materials in order to be used for the manufacture of new concrete complying the requirements of Standard EN 206-1, most European countries have integrated their current Technical Standards for Construction with recommendations enabling the use of coarse recycled concrete aggregates, within certain replacement limits in relation to the strength class, to produce concrete for structural use. For instance, in Italy, this use is allowed within the limits reported in Table 1. However, according to Italian Technical Standards, recycled aggregates have to be chemically and physically characterized prior to their use in concrete, as well as the concrete mixture made with recycled aggregates has to be qualified and proved through laboratory tests as a preliminary step. This means that, in spite of the standard-setter's intent aiming at a new performance standard, Table 1 proves to be prescriptive; and, the additional characterization required for the recycled aggregates proves to be at least protectionist. Finally, the regulation stating that the production control tests of the recycled aggregates must be carried out every 100 tons of produced aggregate may contribute to discourage their use.

Table 1. Limits for use of recycled materials from construction and demolition waste.

\begin{tabular}{|l|c|c|}
\hline \multicolumn{1}{|c|}{ Origin of the recycled material } & Concrete strength class (MPa) & Allowed rate \\
\hline Building demolition (rubble) & $=8 / 10$ & Up to $100 \%$ \\
\hline $\begin{array}{l}\text { Only concrete and reinforced concrete } \\
\text { demolition }\end{array}$ & $\leq 30 / 37$ & $\leq 30 \%$ \\
\hline $\begin{array}{l}\text { Concrete reuse inside qualified precast plants } \\
\text { - all strength classes }\end{array}$ & $\leq 20 / 25$ & Up to $60 \%$ \\
\cline { 2 - 3 } Concrete $>45 / 55$ & Same original strength class & Up to $15 \%$ \\
\cline { 2 - 3 } & & Up to 5\% \\
\hline
\end{tabular}

Within this context, the use of recycled aggregates, in order to limit the use of non-renewable natural resources, has not been popular; and, their availability on the market has been even reduced. 
A recent survey carried out among the building contractors in Italy [ATECAP 2013], the reasons for not using the recycled aggregates are, in order of importance:

- shortage or even a lack of demand for ready-mixed concrete produced by using recycled aggregates;

- uncertainty on technical characteristics of the recycled aggregates;

- difficulty in obtaining recycled aggregates;

-incompatibility of the properties of recycled aggregates with the technical norms of concrete production;

- limited availability of recycled aggregates in the area of jurisdiction; and,

- limited knowledge about development of proper concrete mixtures.

On the other hand, interesting data on the production of aggregates, including the recycled aggregates, have been published recently [European Commission 2010]. These data have shown a noticeably different utilization of recycled aggregates from country to country (Figure 1). This is believed to be due to different policies of waste management (e.g., taxes for landfill disposal) and limitations for the use of natural resources (e.g., taxes on quarried natural aggregates). Where these taxes are higher, the recycling rates are higher.

Many European countries have imposed taxes on natural aggregates with the aim of preserving natural resources to encourage the replacement of natural with recycled aggregates. This taxation has a direct effect on the price ratio between natural and recycled aggregates. It is generally considered a more effective way with respect to taxes on the waste disposal. However, this can increase the risk of illegal disposal. In the economic literature on the subject, taxes on natural resources are not always widely agreed, since the introduction of new taxes can involve negative effects in case of market weakness. In any case, the limitation to the opening of new quarries for the planning of mining activities contributes to a move towards recycled aggregates, since the unavoidable increase in the price of natural aggregates will involve the search for new strategies of reusing existing materials.

In many European countries, the separation, at the site of construction and demolition materials into specific fractions, is mandatory. Selective demolition and separation of materials on a site allow to produce a higher quality waste, with a higher potentiality of being reused as construction material. Due to the additional work for the fractions separation, the process is usually longer and more expensive; but, it also promotes new professional and occupational opportunities. Generally, costs related to selective demolition are on average 20 to $25 \%$ higher than common demolition. Of course, materials obtained by selective demolition involve lower costs for their disposal in landfills or recycling plants. Furthermore, the opportunity of putting again on the market reusable materials and the minimization of waste disposal in landfill lead to compensate the higher costs of selective demolition.

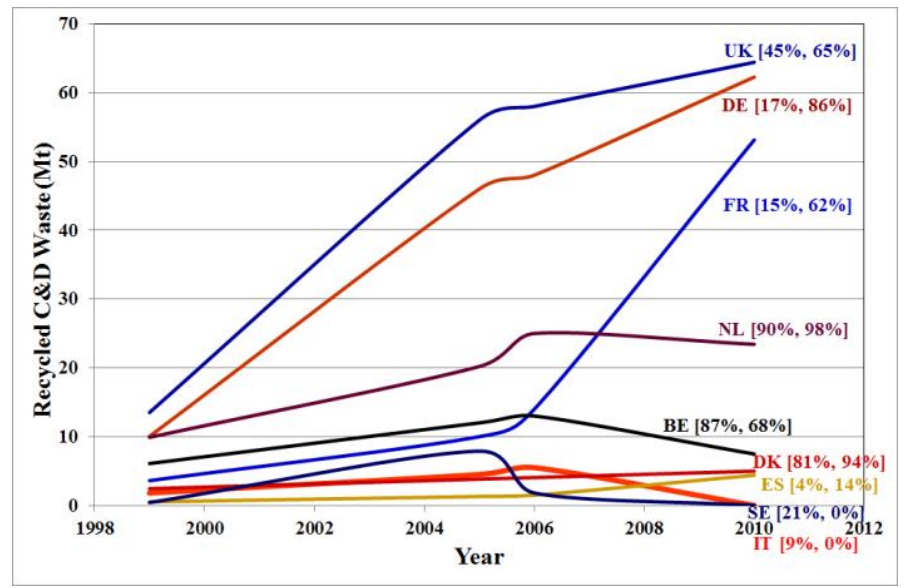

Figure 1. Produced amounts and recycling mean rates $(1999,2010)$ of C\&DW in European countries 
It is evident that the reasons for the missed use of recycled aggregates are not ascribable to technical or technological issues, but to regulatory, economic, administrative, and legislative issues. Indeed, if on the one hand the technical standards authorize the use of recycled aggregates to produce concrete for structural use, then on the other they complicate matters because of specific recommendations that prove unnecessarily protective, at times illogical, and unjustified. This may discourage the use of recycled aggregates. Unavoidably, this makes the designer suspicious and not willing to use such aggregates. Furthermore, the availability of recycled aggregates might be lacking or even null in the absence of governmental directives, which should be able to modify the market of these new resources, enforce the local administration obligations, and repress any illegal exploitation or disposal.

\section{THE TECHNICAL ISSUE AND THE PRECONCEPTION TO OVERCOME}

In order to overcome a preconception, that may no longer be justifiable in the perspective of a sustainable development, the behavior under cyclic loading of beam-column joints (Figure 2) made of concrete prepared with coarse recycled concrete aggregates has been analyzed [Letelier and Moriconi 2014]. The joint design was carried out taking into account that the lower tensile strength and elastic modulus of the recycled aggregate concrete could induce a different failure mechanism of the beamcolumn joint (Figure 3).

The results of this experimentation, carried out on elements of almost full sizes, proved that, by adopting appropriate expedients of calculation, taking into account the different shear behavior and the different stiffness of the structural elements made of recycled aggregate concrete, this kind of joint can achieve adequate ductility values and toughness during loading cycles simulating the seismic action. Indeed, the higher deformability of the recycled aggregate concrete allows to achieve the same ductility level of the ordinary concrete in spite of the lower tensile strength.

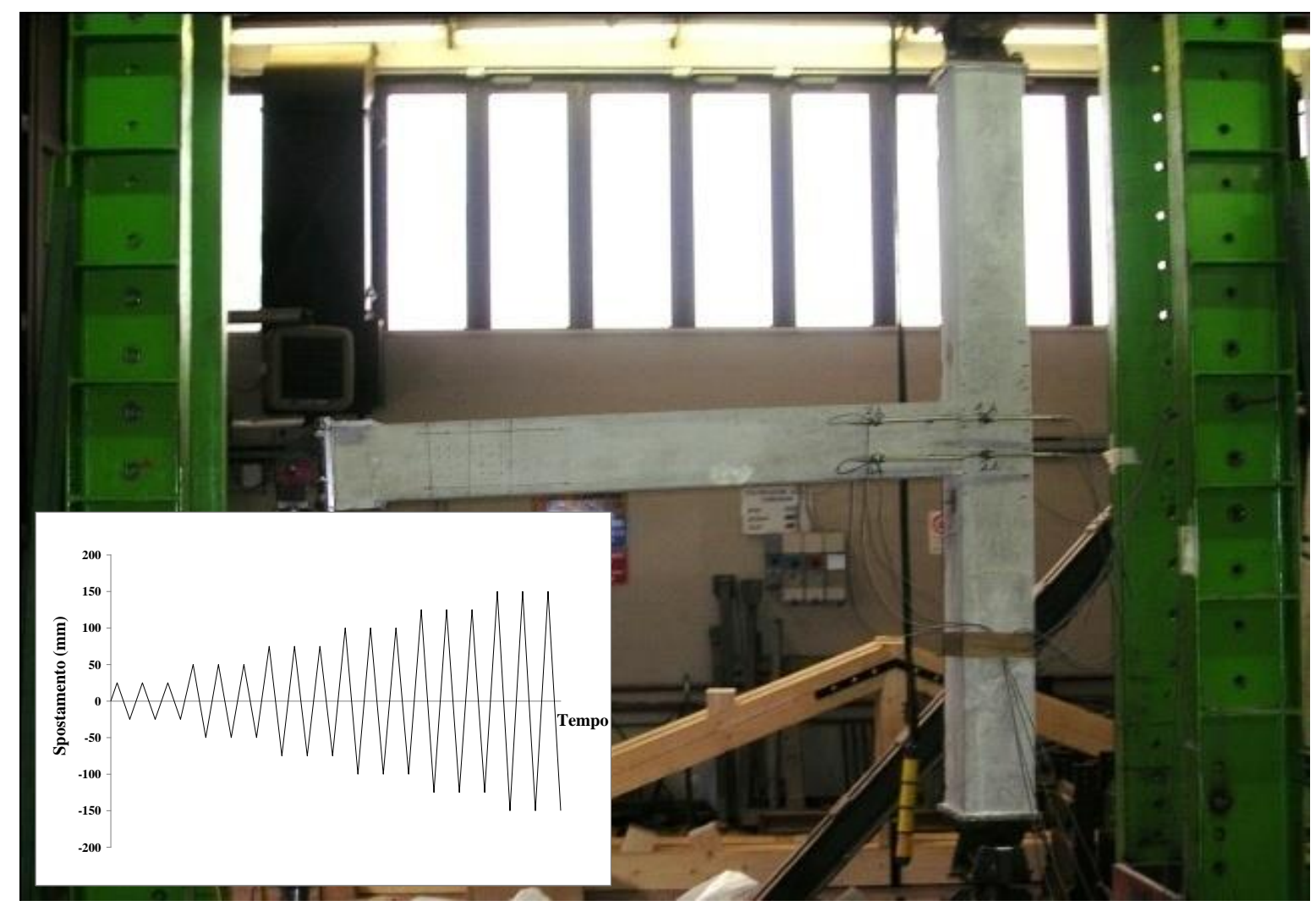

Figure 2. Outline of the concrete beam-column joint under test and diagram of the imposed displacements with time. 
In particular, the analysis of the hysteresis curves shows that, away from the elastic range and then for the highest imposed displacements, a higher aggregate interlock effect along the cracks in the recycled aggregate concrete occurs because of the more rough surface of the recycled aggregates. This effect contributes to increase in the shear strength of recycled aggregate concrete, since higher force values are achieved for the maximum displacement.
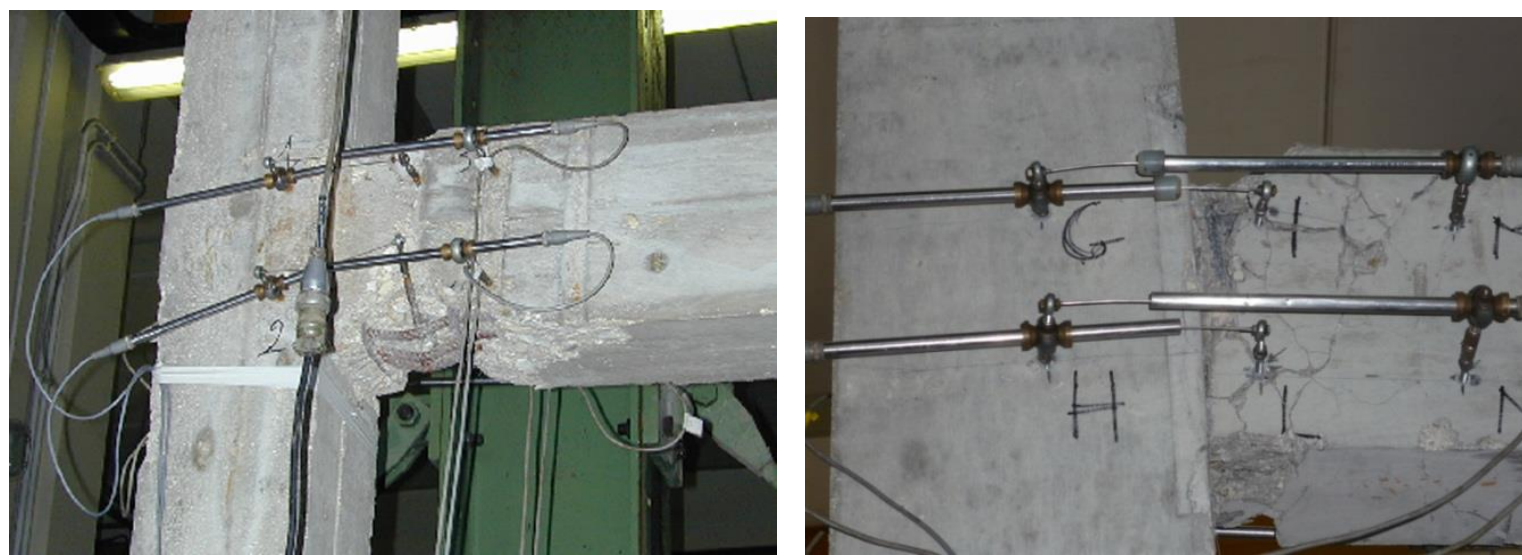

\section{Figure 3. Deterioration pattern in the joint made of ordinary concrete (left) and in the joint made of recycled aggregate concrete (right), with the same strength class.}

The fulfilling behavior of the recycled aggregate concrete under cyclic loading does not impair its suitability, for reinforced concrete structures in seismic areas, though proper account should be taken for its shear strength and stiffness. Therefore, the recycled aggregate concrete does not justify any technical or design alibis which could prevent or even advise against its current use.

\section{CONCLUSION}

History teaches that the construction technology has often resorted to more or less innovative and successful procedures of recovering and reusing waste materials. However, recently, due to a consumerist euphoria, induced by the economic expansion in the industrialized countries and the market widening, has led to forget, or even reject, that judicious experience in favor of an indiscriminate and uncontrolled exploitation of natural resources, as well as an arrogant improper utilization of the territorial area.

The unavoidable threat of an irreversible crisis of nonrenewable natural resources, accompanied by an always more alarming environmental deterioration, however predictable, motivates an increasing number of researchers to search for alternative solutions, reconsidering the opportunity of reusing waste materials, otherwise disposed in landfill. These investigations have, in particular, widely reaffirmed the feasibility and the effectiveness of the use of recycled materials in concrete, for structural use and other applications, and in construction materials, in general.

Therefore, only preconceptions, culturally unjustified, and the lack of responsible political addresses prevent a design opportunity unavoidable for a sustainable development.

\section{REFERENCES}

ATECAP (2013). "ATECAP Report on the Use of Recycled Aggregates in the Production of ReadyMixed Concrete" (in Italian), September 2013.

Bassan, M., Menegotto, M., and Moriconi, G. (2006). "Precast Structural Concrete with Recycled Aggregates", Proceedings of the Second fib Congress, Naples, Italy, 5-8 June 2006, ID 6-19. 
Corinaldesi, V., and Moriconi, G. (2003). "The Use of Recycled Aggregates from Building Demolition in Self-Compacting Concrete", Proceedings of the 3rd International RILEM Symposium on SelfCompacting Concrete, Reykjavik, Iceland, 17-20 August 2003, O. Wallevik and I. Nielsson eds., RILEM Publication s.a.r.l., Bagneux, France, 251-260.

Corinaldesi, V., and Moriconi, G. (2010). "Characterization of Mechanical and Elastic Behaviour of Concretes Made of Recycled-Concrete Aggregates", The Third International Conference on Engineering for Waste and Biomass Valorisation (WasteEng10), Beijing, China, May 17-19, 2010, A. Nzihou and H. Liu eds., Ecole des Mines d'Albi-Carmaux, Albi, France, 048-C.

European Commission (2010) (DG ENV) - Service Contract on Management of construction and demolition waste - SR1. May 2010.

Ho, N., Lee, Y., Lim, W., Zayed, T., Chew, K., Low, G., and Ting, S. (2013). "Efficient Utilization of Recycled Concrete Aggregate in Structural Concrete", Journal of Materials in Civil Engineering, 25(3), 318-327.

Letelier Gonzaléz, V.C., and Moriconi G. (2014). "The influence of recycled concrete aggregates on the behavior of beam-column joints under cyclic loading", Engineering Structures, 60, 148-154.

Malešev, M., Radonjanin, V., and Marinković, S. (2010). "Recycled Concrete as Aggregate for Structural Concrete Production", Sustainability, 2(5), 1204-1225.

Malhotra, V.M. (1978). "Use of recycled concrete as new aggregate", Proceedings of the Symposium on Energy and Resource Conservation in the Concrete Industry, CANMET Rep. No. 76-8, CANMET, Ottawa, Canada, 4-16.

Mehta, P.K. (1997). "Bringing the concrete industry into a new era of sustainable development", Proceedings of the Mario Collepardi Symposium on Advances in Concrete Science and Technology, P.K. Mehta ed., Roma, Italy, October 8, 1997, 49-67.

Mehta, P.K. (1999). "Concrete technology for sustainable development - An overview of essential principles", Proceedings of the International Symposium on Concrete Technology for Sustainable Development in the Twenty-First Century, Hyderabad, India, February 9-11, 1999, P.K. Mehta ed., Radha Press, New Delhi, India, 1-22.

Mehta, P. K. (2009). "Global Concrete Industry Sustainability", ACI Concrete International, 31(2), 4548.

Moriconi, G. (2005). "Aggregate from Recycled Concrete and Demolition Wastes", Proceedings of the Second International Symposium on Concrete Technology for Sustainable Development with Emphasis on Infrastructure, compiled by N. Bhanumathidas \& N. Kalidas, Hyderabad, India, February 27 - March 3, 2005, 543-555.

Naik, T.R., and Moriconi, G. (2005). "Environmental-Friendly Durable Concrete Made with Recycled Materials for Sustainable Concrete Construction", Proceedings of the Three-Day International Symposium on Sustainable Development of Cement, Concrete and Concrete Structures, Toronto, Canada, October 5-7, 2005, V.M. Malhotra and K. Sakai eds., 485-505.

RILEM (1992). "Recycling of Demolished Concrete and Masonry", Report of Technical Committee 37-DRC on Demolition and Reuse of Concrete, RILEM Report 6 (Ed. T.C. Hansen), E \& FN Spon, London, Great Britain. 
Sani, D., Moriconi, G., Fava, G., and Corinaldesi, V. (2005). "Leaching and mechanical behaviour of concrete manufactured with recycled aggregates", Waste Management, 25(2), 177-182.

Tittarelli, F., and Moriconi, G. (2002). "The Effect of Fly Ash and Recycled Aggregate on the Corrosion Resistance of Steel in Cracked Reinforced Concrete", Proceedings of the 9th International Conference on Durability of Building Materials and Components, Brisbane, Queensland, Australia, March 17-20, 2002, Paper 70. 